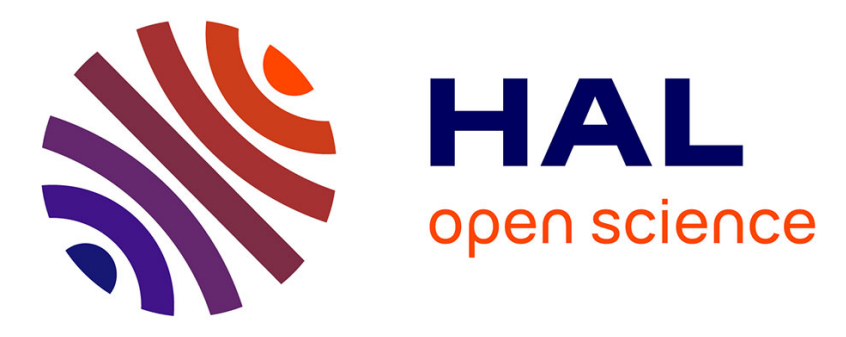

\title{
The Impacts of Quick Response in a Dual-Channel Supply Chain
}

\author{
Huihui Zhang, Danqin Yang
}

\section{To cite this version:}

Huihui Zhang, Danqin Yang. The Impacts of Quick Response in a Dual-Channel Supply Chain. IFIP International Conference on Advances in Production Management Systems (APMS), Aug 2018, Seoul, South Korea. pp.89-96, 10.1007/978-3-319-99707-0_12 . hal-02177869

\section{HAL Id: hal-02177869 \\ https://hal.inria.fr/hal-02177869}

Submitted on 9 Jul 2019

HAL is a multi-disciplinary open access archive for the deposit and dissemination of scientific research documents, whether they are published or not. The documents may come from teaching and research institutions in France or abroad, or from public or private research centers.
L'archive ouverte pluridisciplinaire HAL, est destinée au dépôt et à la diffusion de documents scientifiques de niveau recherche, publiés ou non, émanant des établissements d'enseignement et de recherche français ou étrangers, des laboratoires publics ou privés. 


\title{
The impacts of quick response in a dual-channel supply chain
}

\author{
Huihui Zhang and Danqin Yang \\ School of Economics and Management, Nanjing University of Science \& Technology, Nanjing \\ 210094, China \\ yangdanqin@163. com
}

\begin{abstract}
We consider the quick response (QR) in a dual-channel supply chain in which a manufacturer sells products through both its own direct channel and a retailer. With $\mathrm{QR}$, the retailer has an opportunity to reorder after the random demand is realized and the manufacturer is able to reproduce after that. We characterize the equilibrium decisions for each channel and investigate the impacts of $\mathrm{QR}$ on the decisions and profits. Through numerical analysis, we show that QR may be beneficial to the manufacturer whereas either increases or decreases the optimal expected profit of the retailer. In addition, the supply chain is able to achieve Pareto improvement with QR under certain conditions.
\end{abstract}

Keywords: Dual-Channel Supply Chain, Quick Response, Game Theory.

\section{Introduction}

With the development of e-commerce, it is a growing trend for manufacturers to open up direct channels. Many papers showed that operating direct channel may increase the profits of a firm and its downstream enterprise (Arya et al. 2007, Dumrongsiri et al. 2008). Plenty of companies have established dual-channel networks, such as Apple and Huawei. In last decades, products' life cycles are increasingly shortened and some categories are eliminated from the market so quickly that it's not sensible to keep too many stocks in both direct and retail channel. The quick response originated in the US apparel industry aims to respond to the demand changes better. Iyer and Bergen (1997) evaluated the effect of reducing delivery time through QR and found that QR can increase the retailer's profit while damage the manufacturer's profit. The fast fashion retailer, Zara's practice shows that $\mathrm{QR}$ is a critical factor for reducing the inventory risk. Although the QR systems may increase the cost of manufacturers and retailers, it mitigates the demand uncertainty and increases the sales profits.

Retailers can postpone product ordering until the time closer to the selling season making the demand forecasts and corresponding inventory decisions match better (Fisher et al. 2001). Caro and Martínez-de-Albéniz (2010) considered the retailer competition with demand spillover and found the $\mathrm{QR}$ is more profitable when the demand uncertainty is higher or the cross-temporal demand correlations are bigger. Li and $\mathrm{Ha}$ (2008) assumed the competitive manufacturers rely on initial inventory and 
QR ability to solve the problem of demand uncertainty. Lin and Par-laktürk (2010) analyzed the value of QR in supply chain with one manufacturer and two competing retailers. None of the above literature studied QR in dual-channel supply chain and our paper fills this gap. Our paper is the first to investigate QR in a dual-channel supply chain. Also, almost all literature only considers QR for sellers, whereas we study the pricing and inventory strategy assuming that QR is applied by the retailer and the manufacturer simultaneously. Furthermore, we show that the manufacturer's profit may be improved and the supply chain could achieve Pareto improvement under QR.

\section{The basic model}

We develop a two-stage dynamic programming model in dual-channel supply chain in which the second stage is a static game. The manufacturer sells products through its own direct channel at the direct price $p_{m}$ and the retailer at the wholesale price $w$. The quantity reserved for the direct channel (i.e., direct inventory) is $q_{m}$. The retailer decides to order $q_{r}$ units and sells to consumers at the retail price $p_{r}$. Due to demand uncertainty, both channels may be out of stock during the selling season. In that case, QR allows the manufacturer to start a possible QR production with a quantity of $q_{m}^{\prime}$ (i.e., QR inventory) and the retailer to place a possible QR order with a quantity of $q_{r}^{\prime}$. The unit early and QR production cost of the manufacturer is $c$ and $c_{q r}$, where $c_{q r}>c$. For a unit $\mathrm{QR}$ order, the retailer is charged by $w+e$, where $e$ is the $\mathrm{QR}$ order fee, indicating that the retailer pays more for the QR order than the initial order. After the selling season, unsold products are disposed by a unit salvage value $s$. As is shown in Fig. 1, the sequence of the events is as follows:

(i) In the first stage, the manufacturer decides the wholesale price $w$;

(ii) In the second stage, the manufacturer jointly decides the direct price $p_{m}$ and the direct inventory $q_{m}$, and meanwhile the retailer jointly decides the retail price $p_{r}$ and initial order quantity $q_{r}$.

All decisions above were decided before the selling season. We will use the notations listed in Table A-1 in the Appendix to define our problem.

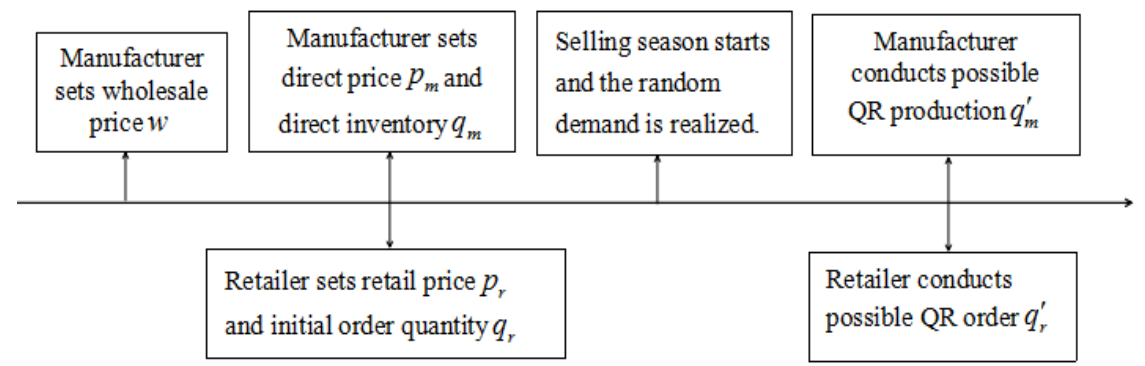

Fig. 1. The sequence of the events in the QR model. 
Similar to Li et al. (2016), the demand function of the direct and retail channel is given by $d_{m}=(1-\theta)(a+\varepsilon)-r p_{m}+t p_{r}$ and $d_{r}=\theta(a+\varepsilon)-r p_{r}+t p_{m} . \theta$ is the retailer's market share. The demand includes the certain part $a$ and the random part $\varepsilon$ which distributes on $U[-b, b]$ where $0 \leq b<a$. According to Li, Zhang and Yan (2012), the demand of many products, e.g., agricultural seeds and festival souvenirs, conforms to the uniform distribution if the life cycle is short and the demand intervals can be inferred from the past data. To provide an transformation of the inventory decisions, we define $z_{m}, z_{r}$ and $z_{m r}$ as inventory factors representing the product quantity ordered to satisfy the stochastic portion of the demand, where $q_{m}=(1-\theta)\left(a+z_{m}\right)-r p_{m}+t p_{r}$, $q_{r}=\theta\left(a+z_{r}\right)-r p_{r}+t p_{m}$ and $q_{m}+q_{r}=a+z_{m r}-(r-t)\left(p_{m}+p_{r}\right)$.

We assume the scenario where the retailer is out of stock before the manufacturer as $\mathrm{RO}$, whereas the scenario where the manufacturer is out of stock before the retailer as MO. Whether stock-out occurs in the retailer or the manufacturer, it will be meet completely in both direct and retail channels through QR. In RO, if $z_{r}<\varepsilon \leq z_{m r}$, the retailer places QR order with a quantity of $q_{r}^{\prime}$ where $q_{r}^{\prime}=\theta\left(\varepsilon-z_{r}\right)$ and the manufacturer does not start QR production. For $\varepsilon>z_{m r}$, QR is conducted on both channels where $q_{m}^{\prime}=\varepsilon-z_{m r}, q_{r}^{\prime}=\theta\left(\varepsilon-z_{r}\right)$ and for $\varepsilon \leq z_{r}$, neither channel will conduct QR. In MO, if $z_{m}<\varepsilon \leq z_{r}$, the manufacturer conducts QR production with a quantity of $q_{m}^{\prime}$ where $q_{m}^{\prime}=(1-\theta)\left(\varepsilon-z_{m}\right)$ while the retailer does not place QR order. QR is conducted on both channels if $\varepsilon>z_{r}$, and is not conducted by either channel if $\varepsilon \leq z_{m}$.

According to the above, the manufacturer's expected profit in $\mathrm{RO}$ is:

$$
\begin{aligned}
\pi_{m}^{q r}= & p_{m} \mathrm{E}\left(d_{m}\right)+w q_{r}+(w+e) q_{r}^{\prime}-c\left(q_{m}+q_{r}\right)-c_{q r} q_{m}^{\prime}+s \mathrm{E}\left(q_{m}-d_{m}\right)^{+} \\
& +s \int_{z_{r}}^{\theta z_{r}+(1-\theta) z_{m}}\left(\theta z_{r}+(1-\theta) z_{m}-\varepsilon\right) f(\varepsilon) d \varepsilon
\end{aligned}
$$

where $\mathrm{E}(\cdot)$ is the expectation operator and $x^{+}=\max (x, 0)$. The manufacturer's expected profit in MO is:

$$
\pi_{m}^{q r}=p_{m} \mathrm{E}\left(d_{m}\right)+w q_{r}+(w+e) q_{r}^{\prime}-c\left(q_{m}+q_{r}\right)-c_{q r} q_{m}^{\prime}+s \mathrm{E}\left(q_{m}-d_{m}\right)^{+}
$$

The retailer's expected profit is the same in both scenarios which is:

$$
\pi_{r}^{q r}=p_{r} \mathrm{E}\left(d_{r}\right)-w q_{r}-(w+e) q_{r}^{\prime}+s \mathrm{E}\left(q_{r}-d_{r}\right)^{+}
$$

Note that we use the superscript 'qr' to represent the scenario with QR throughout this paper. By using backward induction, we can obtain the global optimum solutions in Propositions 1-2. Proofs of all propositions are given in the Appendix.

Proposition 1. With QR, given a wholesale price $w$ of the first stage, the optimal direct price $p_{m}^{q r^{*}}(w)$, direct inventory $q_{m}^{q r^{*}}(w)$, retail price $p_{r}^{q r^{*}}(w)$ and initial order quantity $q_{r}^{q r^{*}}(w)$ are given by: 
a) If $w \geq w_{E}, p_{m}^{q r^{*}}(w)=\bar{p}_{m}^{q r^{*}}(w), q_{m}^{q r^{*}}(w)=\bar{q}_{m}^{q r^{*}}(w)=(1-\theta)\left(a+\bar{z}_{m}^{q r^{*}}(w)\right)-r \bar{p}_{m}^{q r^{*}}(w)+t \bar{p}_{r}^{q r^{*}}(w)$, $p_{r}^{q r^{*}}(w)=\bar{p}_{r}^{q r^{*}}(w), q_{r}^{q r^{*}}(w)=\bar{q}_{r}^{q r^{*}}(w)$;

b) If $w<w_{E}, p_{m}^{q r^{* *}}(w)=\tilde{p}_{m}^{q r^{*}}(w), q_{m}^{q r^{*}}(w)=\tilde{q}_{m}^{q r^{* *}}(w)=(1-\theta)\left(a+\tilde{z}_{m}^{q r^{*}}\right)-r \tilde{p}_{m}^{q r^{* *}}(w)+t \tilde{p}_{r}^{q r^{*}}(w)$, $p_{r}^{q r^{*}}(w)=\tilde{p}_{r}^{q r^{*}}(w), q_{r}^{q r^{*}}(w)=\tilde{q}_{r}^{q r^{*}}(w) ;$

where $\quad w_{E}=\frac{c-s}{c_{q r}-c} e+s, \quad \bar{p}_{m}^{q r^{*}}(w)=\tilde{p}_{m}^{q r^{*}}(w)=\frac{[2(1-\theta) r+\theta t] a+3 r t w+2 r(r-t) c}{4 r^{2}-t^{2}}$, $\bar{p}_{r}^{q r^{*}}(w)=\tilde{p}_{r}^{q r^{*}}(w)=\frac{[2 \theta r+(1-\theta) t] a+\left(2 r^{2}+t^{2}\right) w+t(r-t) c}{4 r^{2}-t^{2}}$

$\bar{q}_{r}^{q r^{*}}(w)=\tilde{q}_{r}^{q r^{*}}(w)=\theta\left(a+\bar{z}_{r}^{q r^{*}}(w)\right)-r \bar{p}_{r}^{q r^{*}}(w)+t \bar{p}_{m}^{q r^{*}}(w), \bar{z}_{m}^{q r^{*}}(w)=\frac{2 b}{1-\theta}\left(\frac{c_{q r}-c}{c_{q r}-s}-\frac{\theta e}{w+e-s}\right)-b$, $\bar{z}_{r}^{q r^{*}}(w)=\tilde{z}_{r}^{q r^{*}}(w)=\frac{2 b e}{w+e-s}-b$ and $\tilde{z}_{m}^{q r^{*}}=2 b \frac{c_{q r}-c}{c_{q r}-s}-b$.

Considering the optimal responses to the wholesale price, we obtain the optimal wholesale price for the manufacturer in the following proposition.

Proposition 2. With QR, the optimal wholesale price $w^{q r^{*}}$ is given by:

a) For $\bar{w}^{q r} \geq w_{E}$, the manufacturer sets $w^{q r^{*}}=\bar{w}^{q r}$;

b) For $\bar{w}^{q r}<w_{E}<\tilde{w}^{q r}$, the manufacturer sets $w^{q r^{*}}=w_{E}$;

c) For $\tilde{w}^{q r} \leq w_{E}$, the manufacturer sets $w^{q r^{*}}=\tilde{w}^{q r}$, where

$\bar{w}^{q r}$ and $\tilde{w}^{q r}$ satisfy $\theta a-r p_{r}^{q r^{*}}+t \bar{p}_{m}^{q r^{*}}+\frac{\theta\left(z_{r}^{q r^{*}}+b\right)^{2}}{4 b}+\frac{2 r^{2}+t^{2}}{4 r^{2}-t^{2}}\left[t\left(\bar{p}_{m}^{q * *}-c\right)-r\left(\bar{w}^{q r}-c\right)\right]=0$ and $\theta a-r p_{r}^{q r^{*}}+t \tilde{p}_{m}^{q r^{*}}+\frac{\theta\left(z_{r}^{q r^{*}}+b\right)^{2}}{4 b}+\left[t\left(\tilde{p}_{m}^{q r^{*}}-c\right)-r\left(\tilde{w}^{q r}-c\right)\right] \frac{2 r^{2}+t^{2}}{4 r^{2}-t^{2}}-\frac{2 b \theta e\left(c_{q r}-c-e \frac{c_{q r}-s}{\tilde{w}^{q r}+e-s}\right)}{\left(\tilde{w}^{q r}+e-s\right)^{2}}=0$.

The manufacturer and the retailer have the same relative shortage costs when the value of wholesale price is $w_{E}$. If $\bar{w}^{q r}>w_{E}$, the retailer's relative shortage cost is smaller than that of the manufacturer. Thus, the retailer will be easier to be out of stock than the manufacturer and the equilibrium occurs in RO. Similarly, if $\tilde{w}^{q r}<w_{E}$, the manufacturer's relative shortage cost is smaller than that of the retailer which results in a lower direct inventory so that the equilibrium occurs in MO.

Next, we consider the benchmark model with no QR. The sequence of events is the same as that in QR model except for not requiring the last stage. Similarly, we solve it by using backward induction. The manufacturer's expected profit is:

$$
\pi_{\mathrm{m}}=p_{m} \mathrm{E}\left[\min \left(q_{m}, d_{m}\right)\right]+w q_{r}-c\left(q_{m}+q_{r}\right)+s \mathrm{E}\left(q_{m}-d_{m}\right)^{+}
$$

The retailer's expected profit is:

$$
\pi_{\mathrm{r}}=p_{r} \mathrm{E}\left[\min \left(q_{r}, d_{r}\right)\right]-w q_{r}+s \mathrm{E}\left(q_{r}-d_{r}\right)^{+}
$$


Proposition 3. Assume $(1-\theta)(a-b)-r c>0$ and $\theta(a-b)-r w>0$, we have

a) For a given wholesale price $w$, the optimal direct price, retail price, direct inventory and initial order quantity are given below:

$$
\begin{aligned}
& p_{m}^{*}(w)=\frac{[2(1-\theta) r+\theta t] a+3 r t w+2 r(r-t) c}{4 r^{2}-t^{2}}-\frac{2 r(1-\theta)\left(z_{m}^{*}(w)-b\right)^{2}+\theta t\left(z_{r}^{*}(w)-b\right)^{2}}{4 b\left(4 r^{2}-t^{2}\right)}, \\
& p_{r}^{*}(w)=\frac{[2 \theta r+(1-\theta) t] a+\left(2 r^{2}+t^{2}\right) w+(r-t) t c}{4 r^{2}-t^{2}}-\frac{(1-\theta) t\left(z_{m}^{*}(w)-b\right)^{2}+2 \theta r\left(z_{r}^{*}(w)-b\right)^{2}}{4 b\left(4 r^{2}-t^{2}\right)}, \\
& q_{m}^{*}(w)=(1-\theta)\left(a+z_{m}^{*}(w)-r p_{m}^{*}(w)+t p_{r}^{*}(w)\right), q_{r}^{*}(w)=\theta\left(a+z_{r}^{*}(w)\right)-r p_{r}^{*}(w)+t p_{m}^{*}(w), \\
& \text { where } z_{m}^{*}(w)=2 b \frac{p_{m}^{*}(w)-c}{p_{m}^{*}(w)-s}-b \text { and } z_{r}^{*}(w)=2 b \frac{p_{r}^{*}(w)-w}{p_{r}^{*}(w)-s}-b ;
\end{aligned}
$$

b) The optimal wholesale price satisfies the following first-order condition:

$$
\begin{aligned}
& \theta\left(a+z_{r}^{*}\right)-r p_{r}^{*}+t p_{m}^{*}+\left[t\left(p_{m}^{*}-c\right)-r\left(w^{*}-c\right)\right] A\left(w^{*}\right)+\theta\left(w^{*}-c\right) \frac{2 b A\left(w^{*}\right)\left(w^{*}-s\right)-b\left(p_{r}^{*}-s\right)}{\left(p_{r}^{*}-s\right)^{2}}=0, \\
& A\left(w^{*}\right)=\frac{\left(2 r^{2}+t^{2}-2 \theta r \frac{2 b\left(w^{*}-s\right)}{\left(p_{r}^{*}-s\right)^{2}}\right)\left(4 r^{2}-t^{2}-2(1-\theta) r \frac{2 b(c-s)^{2}}{\left(p_{m}^{*}-s\right)^{3}}\right)+(1-\theta) t \frac{2 b(c-s)^{2}}{\left(p_{m}^{*}-s\right)^{3}}\left(3 r t-\theta t \frac{2 b\left(w^{*}-s\right)}{\left(p_{r}^{*}-s\right)^{2}}\right)}{\left(4 r^{2}-t^{2}-2 \theta r \frac{2 b\left(w^{*}-s\right)^{2}}{\left(p_{r}^{*}-s\right)^{3}}\right)\left(4 r^{2}-t^{2}-2(1-\theta) r \frac{2 b(c-s)^{2}}{\left(p_{m}^{*}-s\right)^{3}}\right)-(1-\theta) t \frac{2 b(c-s)^{2}}{\left(p_{m}^{*}-s\right)^{3}} \theta t \frac{2 b\left(w^{*}-s\right)}{\left(p_{r}^{*}-s\right)^{2}}} .
\end{aligned}
$$

\section{The impacts of quick response}

In this section, we study the impacts of QR in the dual-channel supply chain by numerical examples. The default values of all parameters are given by $a=2000$, $b=500, r=50, t=40, s=0.2, c=1, c_{q r}=1.5$ and $e=0.5$. Firstly, we explore the effects of QR on the optimal decisions and profits of the manufacturer and the retailer for different retailer's market share $\theta$ in Figs. 2-4.
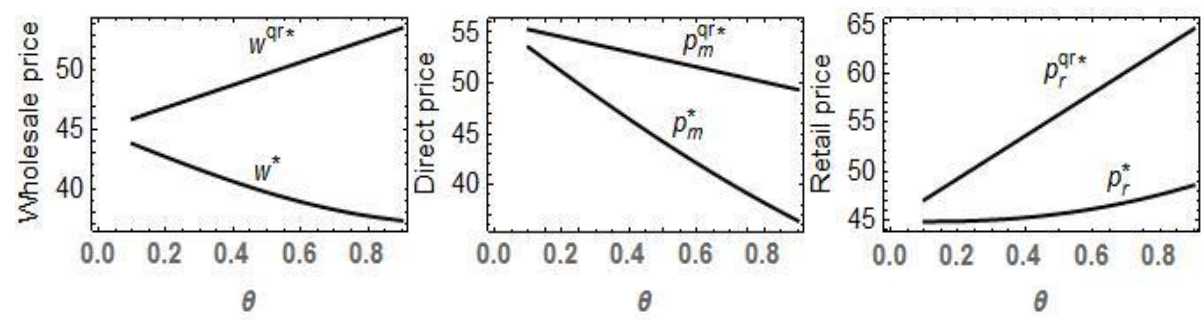

Fig. 2. The impact of $\mathrm{QR}$ on the optimal wholesale price, direct price and retail price. 
We can obtain some interesting observations from Fig. 2. We find that the optimal wholesale price in QR model is substantially larger than that in no QR model. For the manufacturer, providing QR policy to the retailer brings higher production cost gives the reason to propose higher wholesale price. Naturally, the optimal selling prices of both channels are higher with QR. The optimal retail price increases in the retailer's market share because the optimal wholesale price increases in it. The optimal direct price decreases as the retailer's market share increases since the effect of its reduced market share outweighs that of the increased wholesale price.
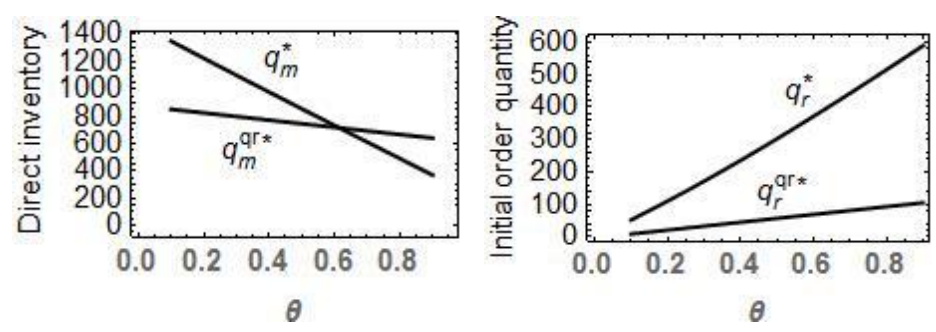

Fig. 3. The impact of QR on the optimal direct inventory and initial order quantity.

For the manufacturer, $\mathrm{QR}$ production allows him to decrease the direct inventory while the retailer's QR order prompts to increase it. From Fig. 3, we find that with $\mathrm{QR}$, the manufacturer's optimal direct inventory is lower than that with no QR when the retailer's market share is low because the effect of QR production exceeds that of the QR order. However, if $\theta$ is sufficiently big, the effect of QR order exceeds that of $\mathrm{QR}$ production and the optimal direct inventory is higher than that with no QR. For the retailer, the higher optimal wholesale price and retail price results in lower initial order quantity. Therefore, the retailer's initial order quantity will be greatly reduced in contrast to that without QR.
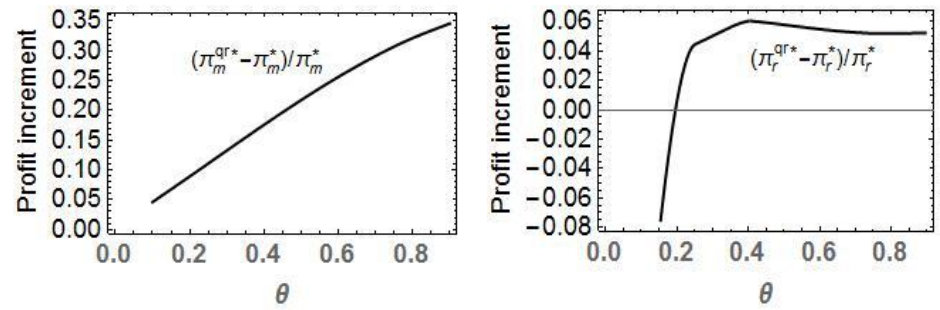

Fig. 4. The impact of QR on the increment of the optimal expected profit of the manufacturer and the retailer.

Form Fig. 4, we find that QR is beneficial to the manufacturer. This is because QR increases the expected sales revenue of both direct and retail channel. Although the manufacturer's production cost increases, it is less than the increase in sales revenue. Moreover, the manufacturer's expected profit increment increases in the retailer's market share. For the retailer, the expected profit might increase or decrease. When the retailer's market share is low, QR hurts the retailer, for the reason that the sales 
revenue increment is less than the procurement cost increment incurred by the QR. As the market share increases, the outcome is reversed and the retailer will benefit from QR. It's interesting to find that there exists Pareto improvement by QR when the market share of the retailer is sufficiently high. That is, QR is easier to implement in this case than other situations because both the manufacturer and the retailer will benefit from QR so that accept it.
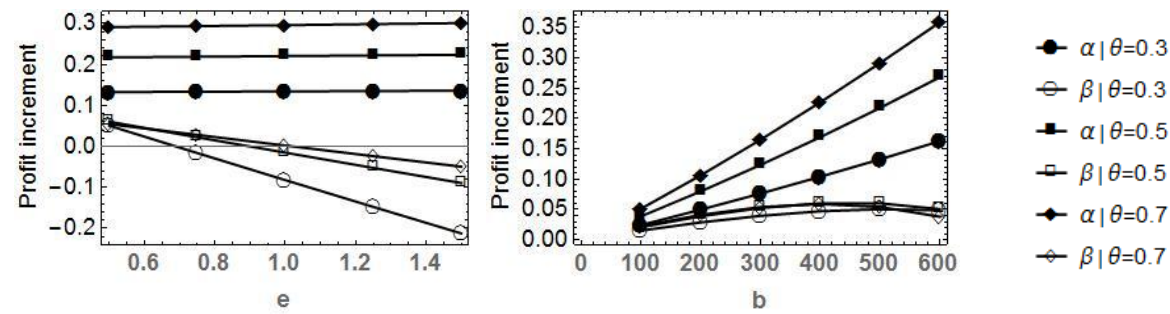

Fig. 5. The impacts of $e$ and $b$ on the increment of the optimal expected profits of the manufacturer and the retailer, where $\alpha=\left(\pi_{m}^{q r^{* *}}-\pi_{m}^{*}\right) / \pi_{m}^{*}, \beta=\left(\pi_{r}^{q r^{*}}-\pi_{r}^{*}\right) / \pi_{r}^{*}$.

From Fig. 5, we show that the manufacturer's optimal expected profit increment with QR increases in the QR order fee, while that of the retailer decreases in it. When the value of $e$ is small, the retailer benefits from $\mathrm{QR}$. Once the $\mathrm{QR}$ order fee exceeds a threshold, the retailer's performance turns worse. We also show that the threshold will increase in the retailer's market share. This is because the retailer's expected sales revenue of QR order increases in its market share. Thus, QR achieves Pareto improvement with a sufficiently small QR order fee. This implies that QR may not be successful when it is hard to executive, e.g., the QR order fee is high. The manufacturer should reduce QR order fee as much as possible to prompt QR.

We find that the manufacturer's optimal expected profit increment increases in the random demand fluctuation range, while that of the retailer first increases in it and then decreases in it. We can explain it as follows: if the random demand is small, the impact from the retailer's increased sales income of QR order decreases; otherwise, the impact from the increased procurement cost increases. Therefore, if the market demand fluctuates too much, it is better for the retailer not to accept QR because the manufacturer may set a high wholesale price.

\section{Conclusions}

The literature on quick response has widely focused on tradition retail channel supply chain and firms' competition while we investigate the value of quick response in a dual-channel supply chain consisting of a manufacturer and a retailer. In this paper, we give the equilibrium decisions and profits of both channels. Our numerical results demonstrate that with QR strategy, the manufacturer could set a higher wholesale and direct price. The retailer reduces the initial order quantity significantly and set a higher retail price. For the manufacturer, direct inventory may not necessarily be reduced 
because of the retailer's QR order. We show that the manufacturer may be benefits from quick response because QR makes the manufacturer's sales revenue of direct and retail channel increase substantially. However, the retailer's expected profit will either be increased or decreased because the retailer has increased sales revenue and procurement cost as well. Finally, we find that QR could achieve Pareto improvement if the retailer's market share is high, the QR order fee is low, or the random demand fluctuation range is either not too big or too small. In the future, considering an endogenous QR wholesale price is a valuable research issue. It would also be interesting to study how strategic consumer behavior influences the value of quick response in a dual-channel supply chain.

\section{Acknowledgement}

This work is supported by (i) National Natural Science Foundation of China under grant 71771123; (ii) Social Science Foundation of Jiangsu Province under grant $15 \mathrm{GLC} 006$.

\section{References}

1. Arya, A.,Mittendorf, B., Sappington, D.: The bright side of supplier encroachment. Marketing Science 26(5): 651-659 (2007).

2. Dumrongsiri, A., Fan, M., Jain, A., et al.: A supply chain model with direct and retail channels. European Journal of Operational Research 187(3): 691-718 (2008).

3. Iyer, A V., Bergen, M E.: Quick response in manufacturer-retailer channels. Management Science 43(4): 559-570 (1997).

4. Fisher, M., Rajaram, K., Raman, A.: Optimizing inventory replenishment of retail fashion products. Manufacturing \& Service Operations Management 3(3): 230-241(2001).

5. Caro, F., Martínez-de-Albéniz, V.: The impact of quick response in inventory-based competition. Manufacturing Service Operation Management 12(3): 409-429 (2010).

6. Li, Q., Ha, A Y.: Reactive capacity and inventory competition under demand substitution. IIE Transactions 40(8): 707-717 (2008).

7. Lin, Y-T., Parlaktürk, A.: Quick response under competition. Production Operation Management 21(3): 518-533 (2012).

8. Li, B., Hou, P W.,Chen, P., et al.: Pricing strategy and coordination in a dual channel supply chain with a risk-averse retailer. International Journal of Production Economics 178:154-168 (2016).

9. Li, K., Zhang, Y D., Yan. J Y.: Supply chain coordination under uniformly distributed market demand-A double contract based on reward and punishment. Chinese Journal of Management Science 20(3):131-137(2012).

10. Ryan, J K., Sun, D., Zhao, X.: Coordinating a Supply Chain With a Manufacturer-Owned Online Channel: A Dual Channel Model Under Price Competition. IEEE Transactions on Engineering Management 60(2):247-259 (2013).

11. Petruzzi, N C., Dada, M.: Pricing and the News Vendor Problem: a Review with Extensions. Operations Research 47(2):183-194 (1999). 